Stoa

Vol. 9 , no. 18,2018 , pp. 11-27

ISSN 2007-1868

\title{
LA NOCIÓN DE AFECTO EN LA FILOSOFÍA DE ANTONIO ROSMINI
}

\author{
JACOB BUGANZA \\ Instituto de Filosofía \\ Universidad Veracruzana \\ jbuganza@uv.mx
}

RESUMEN: El texto versa sobre la noción de affetto en la filosofía de Antonio Rosmini. El trabajo tiene un carácter reconstructivo, y busca sentar bases para investigaciones ulteriores en torno a la vida afectiva humana. El afecto, en general, es un movimiento que se da entre el sujeto y el objeto, despertando este último en aquél un cierto interés o adherencia, que impacta en el hombre en su triple dimensión ontológica. Además de analizar las diversas dimensiones que indica Rosmini en torno al afecto, se pone énfasis en las tres categorías supremas del ser que propone la filosofía rosminiana. Como parte más alta del sistema, se estudia el afecto desde el ser moral, el cual viene a ser la unión dialéctica entre el ser real y el ideal.

PALABRAS CLAVE: Afecto $\cdot$ ser moral $\cdot$ ser real $\cdot$ ser ideal $\cdot$ Rosmini

ABSTRACT: The text studies the notion of affetto in the philosophy of Antonio Rosmini. The work has a reconstructive nature, and seeks to lay the groundwork for further research on human affective life under this perspective. Affection, in general, is a movement that occurs between the subject and the object, awakening a certain interest or adherence, which impacts man's triple ontological dimension. In addition to analyzing the various dimensions that Rosmini indicates around affection, emphasis is placed on the three supreme categories of being proposed by the Rosminian philosophy. As the highest part of the system, affection is studied from the moral being, which becomes the dialectical union between the real and the ideal being.

KEYWORDs: Affection · Moral Being $\cdot$ Real Being $\cdot$ Ideal Being $\cdot$ Rosmini 


\section{Introducción}

En este trabajo se pretende únicamente dar cuenta de la noción de affetto en la filosofía de Antonio Rosmini. Se circunscribe este documento simplemente a dar cuenta de cuál es la noción que funge como base de la diversidad de afectos que se polarizan en la vida anímica del hombre. Esto no descarta, sin embargo, la referencia a la vida puramente animal, sino que es preciso tenerla presente, aunque siempre con referencia al hombre, que es también sujeto animal. El trabajo tiene, entonces, un fin prioritariamente reconstructivo de esta noción, que puede servir para ulteriores investigaciones vinculadas con la vida afectiva humana. Las fuentes en donde se encuentra plasmada la noción de afecto, y la correspondiente afección (affezione) son muy variadas, empero, siguiendo las indicaciones de nuestro maestro Cirillo Bergamaschi, ${ }^{1}$ se buscará plasmar lo esencial de este fenómeno vital en algunas obras emblemáticas. Sobre todo, habrá que tener presentes algunas obras fundamentales del filósofo roveretano, Concretamente su Psicologia, la Antropologia in servizio della scienza morale, la Filosofia del Diritto, y para coronar, la Teosofia.

\section{Primer acercamiento desde las Constituciones}

Curiosamente uno de los textos donde se encuentra plasmada la noción de afecto, que sirve casi como compendio de su pensamiento en torno a este fenómeno, se encuentra en las Constituciones. Habrá que ver, entonces, qué dice este autor sobre este fenómeno humano en uno de sus apartes. Ahí afirma que los afectos humanos son de tres especies. Algunos afectos son tales que, "por ellos, el hombre se adhiere a alguna cosa creada como al propio fin o en modo preponderante", pero piensa que, desde el punto de vista de la ley eterna, son "generalmente pecaminosos", por lo que se debe huir de ellos. ${ }^{2}$ Parece resonar aquí la tesis moderna, muy en boga en su tiempo, de que el hombre posee tendencias afectivas desordenadas por naturaleza. Un segundo tipo de afecto es la adhesión que el hombre tiene por aquellas cosas que, aunque no se adhiera a ellas de tal suerte que prefiera pecar en

${ }^{1}$ Cf. Bergamaschi, Cirillo, L'essere morale nel pensiero filosofico di Antonio Rosmini, La Quercia, Génova, 1982, 250pp.

${ }^{2}$ Rosmini, Antonio, Costituzioni dell'Istituto della Carità, núm. 47, nota. "Per essi l'uomo aderisce a qualche cosa creata come al proprio fine o in modo preponderante". 
vez de dejarlas, logra hacerlas a un lado con una enorme dificultad. Y un tercer tipo o especie de afectos comprende los que no derivan de la determinación de la voluntad, ni de la naturaleza corrompida, sino de la "misma facultad sensitiva de la naturaleza humana" y se pueden llamar, según Rosmini, sensaciones (sensazioni) en vez de afectos. ${ }^{3} \mathrm{Y}$ sobre las sensaciones, tomadas en este sentido, el filósofo roveretano parece profesar neutralidad, aunque puedan servir, en el caso de tener por objeto los oficios divinos, como un estímulo. Ahora bien, se puede interpretar que los afectos, tal como están caracterizados en las Constituciones, permiten entender que, para él, el afecto es un tipo de movimiento anímico, a saber, el que se da en el entrecruce entre un objeto o cosa y el interés subjetivo, pues no de otra manera puede entenderse que el sujeto se "adhiera", al menos de tres formas diversas, a las cosas que despiertan un interés en él, interés que podría definirse como atención, esto es, como un acto de consciencia por el que ésta se concentra en un objeto o aspecto de éste, y que no necesariamente está presente, ${ }^{4}$ a menos de que sea una sensación, ciertamente.

\section{Las afecciones de origen animal}

Ahora bien, si el afecto es un tipo de movimiento anímico, se sigue que en el mundo zoético o puramente animal se encuentran sus fundamentos. En otras palabras, en toda alma se suscitan estos movimientos, por lo cual es posible hablar, de entrada, de afección animal. Y precisamente así acaece en la Antropologia in servizio della scienza morale, en donde asegura, en un interesante parágrafo, que se pretende esquematizar ahora, lo siguiente: (i) el movimiento del animal no procede de inmediato de las sensaciones e imágenes. ¿Qué quiere decirse con esto? Que Rosmini ya distingue, de entrada, entre sensación y afecto, como se ve en las Constituciones, a pesar de la vinculación etimológica entre este último término y el tipo de actividad que se desarrolla en la sensación. La sensación no es otra cosa que el entrecruce entre lo sensible y el sentido; por tanto, se trata de una actividad meramente orgánica. Por ello dice, a nuestro juicio, que la sensación, y las consecuentes

\footnotetext{
${ }^{3}$ Rosmini, Antonio, Costituzioni dell 'Istituto della Carità, núm. 47, nota. "Stessa facoltà sensitiva della natura umana".

${ }^{4}$ Cf. Rosmini, Antonio, Nuovo saggio sull'origine delle idee, núm. 79, 89-90; Psicologia, núm. 1023-1024, 1508.
} 
imágenes que se forman en el animal a partir de ellas, "no hacen más que iniciar los movimientos nerviosos, los cuales afectan la actividad espontánea del alma". ${ }^{5}$ No puede dejar de advertirse lo indicado en torno a la propia vinculación etimológica, que en el fondo conlleva un vínculo real, entre sensación y afecto, pues, como dice el mismo texto: "afectan" los movimientos nerviosos. Sin embargo, no son afectos en sentido pleno, sino condición de posibilidad para otros movimientos, entre los que interesan, de momento, los afectivos.

Después afirma que (ii) la actividad espontánea se eleva para continuar los movimientos, ya referidos. Los movimientos nerviosos "producen primariamente un sentimiento difuso, que yo llamo afección, o también afección universal, puesto que la actividad del alma está esparcida, como vemos, en todo el cuerpo, y por tanto esta afección se expande por todo más o menos" ${ }^{6}$ Debe destacarse que este segundo movimiento anímico tiene todavía los caracteres de la generalidad, por lo cual, como él mismo asienta, se trata de una afección universal, esto es, que afecta a todo el cuerpo con distintas gradaciones, aunque tal vez sin gran matización, de suerte que cabría hablar aquí de una afección rudimentaria. A partir de aquí concluye que (iii) "esta misma difusión del sentimiento y de la actividad es ella una tercera función de la fuerza unitiva del animal, porque en ella más sensaciones e imágenes se funden y contemperan en una sola afección prevalente, que las domina a todas, y que las hace servir todas a ella, la cual es, luego, causa próxima y única de movimientos y operaciones del animal". ${ }^{7}$ El término clave, a nuestro juicio, es contemperare, el cual, aunque pareciera hacer referencia a la temperancia como virtud moral, no significa exactamente eso, sino que se "proporcionan" entre sí los afectos más o menos dispersos en uno solo, que viene a ser prevalente; esto

\footnotetext{
${ }^{5}$ Rosmini, Antonio, Antropologia, núm. 470. "Queste non fanno che iniziare i movimenti nerviosi, i quali affettano l'attività espontanea dell' anima".

${ }^{6}$ Rosmini, Antonio, Antropologia, núm. 470. "Producono primariamente un sentimento diffuso, che io chiamo affezione, od anche affezione universale; perocché l'attività dell'anima è sparsa, como vedemmo, in tutto il corpo, e quindi per tutto più o meno questa affezione si spande".

${ }^{7}$ Rosmini, Antonio, Antropologia, núm. 470. "Ma questa stessa diffusione del sentimento e dell 'attività ella è una terza funzione della forza unitiva dell'animale; perocché in essa, più sensazioni e più immagini si fondono e contemperano in una affezione sola prevalente, che le domina tutte, e che le fa servir tutte a se stessa; la quale è poi cagione prossima ed única de'movimenti ed operazioni dell'animale".
} 
explicaría el movimiento anímico animal, sobre todo sus operaciones, cuando no son éstas erráticas.

Pues bien, los afectos animales pueden, a su vez, clasificarse en tres grupos, los cuales, aunque no perfectamente delimitados por la naturaleza misma del afecto, sí permiten observar algunas diferencias que permiten dar cuenta de las operaciones animales. Rosmini se refiere a estos afectos con el rótulo de clases de afecciones de origen animal en el hombre. Por tanto, se trata de afectos humanos pero de origen animal, y este origen puede ser total o parcialmente así. Cuando nuestro autor se refiere a ellos en la Filosofia del Diritto, comienza hablando de los que son menos animales hasta el que es más totalmente animal, aunque humano. Empero, parece conveniente invertir el orden, como suele hacerse, por ejemplo, en las clasificaciones axiológicas más contemporáneas, ${ }^{8}$ en vistas a captar la complejidad jerárquica de la postura rosminiana.

Aunque se trata de los últimos afectos expuestos dentro de la clasificación de afecciones de origen animal en el hombre, parece que la afección sexual (affezione sessuale) es la más cercana a la animalidad. Se trata de la afección "que une a los dos sexos en vistas a la generación"; 9 pues bien, la afección en este caso es un movimiento anímico por el que el sujeto es atraído por el sexo opuesto, de manera que se suscitan en su interior estos movimientos que ponen en marcha operaciones específicas. Rosmini no se refiere directamente a ellas, pero es claro que se refiere a la posesión sexual, posesión que depende, entonces, del afecto sexual, que se traduce por la atracción física hacia algún individuo del sexo opuesto, pues tiene por finalidad la generación (aunque no alcance este término necesariamente).

Una segunda clase de afecciones de origen animal en el hombre es la "sensual" (sensuale), a la que de entrada el tridentino considera contérmina a la sensible (que se verá enseguida, por ser más compleja y espiritual), y piensa que si esta última llega a ser muy fuerte, pasa de inmediato a la sensual. La afección sexual es descrita como la que "nace en persona del otro sexo, o del mismo, que convergen entre sí,

${ }^{8}$ Cf. De Finance, Joseph, Etica generale, Università Gregoriana, Roma, 1997 (2a. ed.), pp. 54-57.

${ }^{9}$ Rosmini, Antonio, Filosofia del Diritto, vol. II, núm. 1053. "Che unisce i due sessi all 'intento della generazione". 
con el acercamiento y el contacto de sus cuerpos en partes honestas, o con la imaginación de placeres recibidos ahí. Por ello, en un deseo o tendencia a la renovación de tales placeres dicha afección se va resolviendo". ${ }^{10} \mathrm{Al}$ parecer, para penetrar mejor en la naturaleza de esta afección, aunque Rosmini va de los efectos a la causa, es considerarla como el movimiento del ánimo por el cual se pretende renovar el contacto sensitivo con otras personas, a la cual se aprecia deseable: el deseo es definitorio, en cuanto despierta al apetito por la posesión o renovación que atrae la atención subjetiva. Y casos en los que se da el afecto sensual son, precisamente, el contacto corpóreo con alguien más, sin necesariamente implicar proyecciones sexuales, y de ahí el equívoco mismo que se halla en la descripción rosminiana, tal vez deliberada, de afirmar que "convergen entre sí", que también podría traducirse como "conversando entre sí", para brindar la posibilidad del afecto sensual entre personas del mismo sexo, por ejemplo, entre amigos.

La tercera clase de afectos son determinados por el roveretano como "sensibles" (sensibili), y expresamente dice que a ellos reduce "todos aquellos que tienen al mismo tiempo algo del espíritu y algo del animal, pero de estos últimos muy poco, que apenas el hombre se da cuenta de ello; de manera que domina más en ellos [en estos afectos sensibles] la parte espiritual". ${ }^{11}$ Así pues, se trata de movimientos del alma que, aunque tengan participación con la parte animal del hombre, esto es, con la vida orgánica, encuentran su nodo desplazado ya hacia la vida espiritual, de suerte que el foco de interés es algo que tiene ya elementos justamente espirituales. Rosmini estima que hay, a su vez, tres afecciones que cabría tildar de sensibles.

La primera es la afección de admiración deleitable, cuya generación está en la belleza corpórea. El nombre de esta afección, aunque poco atractivo, es muy exacto, pues no se trata de cualquier deleite, sino de uno de admiración justamente, que tiene su origen en los sentidos,

\footnotetext{
${ }^{10}$ Rosmini, Antonio, Filosofia del Diritto, vol. II, núm. 1048. "Che nasce in persone d'altro sesso, o del medesimo, conversanti fra loro, coll 'avvicinamento e col contatto de' loro corpi in parti oneste, o coll 'immaginazione de piaceri indi ricevuti. Quindi in un desiderio o tendenza alla rinnovazione di tali piaceri quell 'affezione si va risolvendo".

${ }^{11}$ Rosmini, Antonio, Filosofia del Diritto, vol. II, núm. 1042. "Tutte quelle che hanno dello spirituale insieme e dell'animale, ma di questo tanto poco, che appena l'uom se n'accorge; di maniera che domina più in esse la parte spirituale".
} 
pero no se reduce a ellos, sino que requiere de la participación del espíritu para ser captado. Un segundo tipo de afecto sensible no tiene un nombre determinado, pero Rosmini parece querer imponerle el de "gracia" (y que se refiere más al interés anímico hacia el otro, más allá de lo físico, aunque lo impregna, como se verá), y es más bien su descripción de lo que lo produce lo que resulta de interés: "La afección que nace toda vez que parece ver en el otro en su aspecto o movimientos, casi como en un espejo, una bella alma, virtud digna, amorosos y nobles sentidos; tal afección es nutrida especialmente por palabras gentiles, las cuales vuelven más claros los indicios de los dotes del espíritu trasluciéndolos en las formas corpórea; así como por gestos cuidadosos, corteses y humildemente altivos". ${ }^{12}$

La tercera clase de afectos sensibles es, en cierto modo, la del enamoramiento, que a veces se confunde, debido a diversos grados de intensidad, con los dos precedentes. Es cuando se enciende de inmediato una atracción misteriosa que conduce a amar a alguien, casi en un arrebato, sin poder darse razón (Rosmini habla en plural en este caso, pues piensa en dos enamorados: "senza poterne dare a sé stesse ben chiara ragione"). En efecto, y retomando la definición original, el afecto no traiciona su esencia, pues no deja de ser un movimiento anímico que despierta un interés en el agente, en este caso uno tan intenso que lo lleva a unirse al amado, y que no por fuerza requiere de la belleza física, pues ésta es relativa y parcial, dado que incluso puede "l'innamoramento nasce[re] anche verso persone per sé deformi". ${ }^{13}$

\section{Las afecciones inteligibles}

Pero hay también afecciones propiamente humanas, o inteligibles si se quiere, y que en cierta medida van más allá de las meramente sensibles. Propongo denominar "afecciones inteligibles" para no confundirlas con las "afecciones intelectuales", pues vendrían a relacionarse como el género con la especie. Pues bien, Rosmini está en concordia

\footnotetext{
${ }^{12}$ Rosmini, Antonio, Filosofia del Diritto, vol. II, núm. 1043, 2. "L'affezone che nasce ogniqualvolta sembra vedere nell 'altrui aspetto o ne'movimenti, quasi in ispecchio, una bell 'anima, dignitosa virtù, amorosi e nobili sensi; la quale affezione bien nutrita specialmente delle gentili parole, le quali rendono più chiari gl 'indizj delle doti dello spirito tralucenti nelle forme corporee; come pure da'gesti ammodati, cortesi, e umilmente alteri".

${ }^{13}$ Rosmini, Antonio, Filosofia del Diritto, vol. II, núm. 1043, 3. "El enamoramiento [puede] nacer incluso hacia personas deformes por sí".
} 
con la idea de que la inteligencia es sentiente, esto es, se afecciona, tesis que, en cierto modo, lo pone en la vanguardia filosófica. Ahora bien, este grupo de afecciones humanas se dividen en tres grupos, nuevamente. Ahora bien, es importante tener presente que Rosmini estudia este grupo de afecciones en el marco de las obras morales, por lo que la referencia al bien honesto se vuelve obligada. Al parecer, es en la Storia comparativa e critica dei sistemi intorno al principio della morale donde se halla un importante pasaje en donde se establece la distinción entre el afecto intelectivo y el racional, aunque están estrechamente vinculados. Al inicio de este importante tratado, Rosmini se pregunta por qué razón una acción, que tomada materialmente en sí misma no es moral, sino análoga a la de los brutos, es al mismo tiempo denominada moral. Esta cuestión recuerda al planteamiento kantiano, en cuanto que hay ciertas condiciones prácticas de posibilidad para poder establecer que un acto externo es moral y que escapan al mero fenómeno (en sentido nuevamente kantiano) en particular. ${ }^{14}$

\footnotetext{
${ }^{14}$ En efecto, la libre voluntad, aunque se determine racionalmente por la ley moral, es precisamente libre porque no está sometida a otra ley que no sea la moralidad misma. La libertad de la causa eficiente de la voluntad no es empírica, como quisiera el empirismo, ni una cualidad psicológica, sino que es trascendental. Es preciso distinguir entre la causalidad como necesidad natural (Naturnotwendigkeit) y la causalidad como libertad. La primera tiene que ver sólo con la existencia de las cosas en cuanto determinables en el tiempo, es decir, con los fenómenos. Si se siguiera el esquema causal natural, de acuerdo con el cual lo que sucede en el tiempo presente está determinado por lo que sucedió en el tiempo pasado, y lo que está en el tiempo pasado no está ya bajo el poder del agente, se seguiría que lo que se está por realizar en el presente no está en el poder del gente; por tanto, la causalidad del agente no sería libre nunca. Por tanto, Kant insiste en la diferencia entre fenómeno y cosa en sí, que trabaja en múltiples obras: a la causalidad según la ley de la causalidad natural correspondería el fenómeno, mientras que la libertad, si quiere ser algo, se refiere al mismo ser considerado como cosa en sí. Es preciso, entonces, admitir que la libertad es trascendental y se finca en la cosa en sí; por ello es que tiene razón Deleuze cuando dice que el conocimiento, al recaer exclusivamente sobre los fenómenos, es forzado, por su propio interés, a pensar en cosas en sí, las cuales fungen como fundamento de los fenómenos sensibles (Deleuze, p. La filosofía crítica de Kant (traducción de Marco Aurelio Galmarini), Cátedra, Madrid, 1997, p. 58). De lo contrario, ¿cómo podría enjuiciarse según la ley moral al ladrón, si su acción tiene lugar sólo, como consecuencia necesaria, de las determinaciones que le preceden? ¿Cómo es que alguien puede ser libre, pues se le enjuicia de acuerdo con la ley, y al mismo tiempo estar sometido, en la misma acción, por la inevitable necesidad natural? Para poder resolver el problema anterior, pide remitirse a lo dicho en la Crítica de la razón pura. A partir de ella se sigue es uno y el mismo sujeto el que, por un lado, está sometido a la necesidad natural, y por tanto al tiempo, al que no puede controlar en tiempo pasado, y el que, por otro lado, tiene consciencia de sí mismo como cosa en sí, es decir, en cuanto se considera a sí mismo como algo que no está sometido a las condiciones del tiempo (es nicht unter Zeitbedingungen steht). Bajo este respecto, se considera a sí mismo como determinable mediante leyes (als
} 
Las causas próximas de las acciones externas, y que tienen carácter moral, tienen en común con los actos que no son morales precisamente estas causas, a saber, el principio afectivo del hombre. Toda actividad externa y, por decirlo así, material, que se efectúa corporalmente, tiene por causa próxima la afección. Pero estas afecciones pueden ser de dos tipos, a saber, sensibles (animales) o inteligibles, sea porque tengan su principio en la dimensión animal del hombre, sea porque la tengan en el principio intelectual. Las afecciones, entonces, tienen un doble origen en el hombre, aunque a veces parezca difícil distinguirlas, y esto se debe, dice el propio roveretano, "a la pobreza de la lengua", como cuando se aplica el término "amor" para afecciones cuyo principio remoto es distinto. Pero, entonces, ¿de dónde proviene el carácter moral de las acciones o actos externos? Ciertamente que si provienen o son causadas sólo e inmediatamente por los afectos animales, la moralidad no puede hallarse en ellas, pues las afecciones puramente animales son ciegas, necesarias e instintivas. Así pues, si quiere encontrarse el carácter moral de las acciones externas, es preciso elevarse a otro orden más allá de los afectos puramente animales, pues no es inteligible caracterizar los actos morales como ciegos, instintivos y necesarios. Por tanto, es preciso alcanzar la dimensión intelectual, que dicho sea de paso, no está del todo desapegada de la animal, sino que en el hombre forman un todo.

Cuando se alcanza la dimensión intelectiva, se cae en la cuenta de que también en este ámbito, como se adelantó, hay afecciones. La inteligencia, en otros términos, es sentiente. Al conocer se afecciona, pero no necesariamente en una dirección o en otra, sino que hay diversas posibilidades para afeccionarse. De lo contrario cabría tildar a estas afecciones como necesarias, ciegas e instintivas. Por el contrario, las afecciones inteligibles sí dependen del sujeto racional, como le llama Kant. Y justamente aquí está la distinción que, a nuestro juicio, el rosminianismo pretende establecer, a saber, entre las afecciones racionales

bestimmbar durch Gezetze), las cuales se da a sí mismo a través de la razón. Desde esta perspectiva nouménica, el sujeto no es nada anteriormente a la determinación de su voluntad, de manera que toda acción suya debe considerarse en la consciencia de su existencia inteligible como consecuencia de su causalidad como noúmeno (als Bestimmungsgrund seiner Kausalität, als Noumens). Es bajo esta perspectiva noumenal que la acción tiene su origen causal en la voluntad del agente, aunque la misma acción pueda considerarse, fenoménicamente, como necesaria, Cf. Kant, Immanuel, Crítica de la razón práctica, pp. 93, 166ss. 
y las irracionales. En efecto, las afecciones inteligibles, al depender de la inteligencia humana, en el sentido de que abarca tanto al entendimiento como a la voluntad, ${ }^{15}$ pueden ser racionales o irracionales. ¿ंDe qué depende la racionalidad o irracionalidad de estas afecciones inteligibles? Y es que, de acuerdo con la racionalidad o irracionalidad que se profese de estas afecciones, depende la moralidad o inmoralidad de ellas mismas. En otros términos, las afecciones inteligibles racionales son moralmente buenas, mientras que las afecciones inteligibles irracionales son moralmente malas. Por ello, nos parece, se pregunta Rosmini, ¿̇en qué consiste la racionalidad de estas afecciones inteligibles (él las llama aquí "intelectivas")? Y afirma que el "amor o cualquier otra afección se dice racional cuando es proporcional al objeto al cual se refiere". ${ }^{16}$

El pasaje decisivo se encuentra un poco más adelante, en el artículo 2, cuando el filósofo tridentino escribe que "El sujeto intelectivo, entonces, percibiendo la entidad de los entes, percibe su valor, y así se comunica con ellos en cuanto al valor, o sea, con el bien que tienen. Por tanto, puede valorarlos, y puede alegrarse de su bondad, en donde se halla la afección racional, no consistiendo la naturaleza de esta afección en otra cosa que en recibir placer y sentir gozo por el bien de los entes percibidos proporcionalmente al bien que ellos tienen, o sea, en sus entidades propias". ${ }^{17}$ Puesto que es un hecho de experiencia que

${ }^{15}$ Para el concepto de "inteligencia humana", Cf. Buganza, J. y R. Cúnsulo, Breve esquema de antropología filosófica, Agape, Buenos Aires, 2013, 172pp.

${ }^{16}$ Rosmini, Antonio, Storia comparativa e critica dei sistemi intorno al principio della morale, Cap. I, a. 1, p. 172. "Un amore o un'altra affezione qualsivoglia si dice ragionevole, cuando ella è proporzionata all'oggetto a cui si riferisce".

${ }^{17}$ Rosmini, Antonio, Storia comparativa e critica dei sistemi intorno al principio della morale, Cap. I, a. 2, p. 177. "Il soggetto intellettivo adunque percependo l'entità degli enti, percepisce il loro pregio, e così comunica con essi quanto al pregio, o sia al bene che hanno. Egli può dunque pregiarli, e può rallegrarsi della loro bontà; nel che sta l'affezione razionale, non consistendo la natura di questa affezione in altro, che in prender piacere e sentir Gaudio del bene degli enti percepiti proporzionatamente al bene loro, o sia alla loro entità". Con esto ganado, es provechoso retornar al artículo 1 para que, a la luz de esta tesis, se visualice la postura rosminiana en torno a estos afectos, porque no sólo entra en juego el intelecto, como facultad aislada, sino toda la inteligencia humana. En el texto recientemente citado, se aprecia un acto que es precisamente del que depende la racionalidad o irracionalidad del afecto inteligible: la valoración. En consecuencia, la valoración, a veces llamada también stima, es el acto que constituye la base afecciones racionales o irracionales. Y es que no pueden ser racionales o irracionales sino porque les precede la operación de la razón; por tanto, la causa próxima de las afecciones inteligibles, racionales o irracionales, es la estimación o valoración que se hace de los diversos objetos que capta el intelecto. Y como consecuencia de esto, puede afirmarse que las afecciones son 
se experimenta esta contrariedad entre las dos estimaciones, se sigue que existen. La racionalidad de la estima práctica, entonces, estriba en concordar con la estima especulativa; si la estima práctica es contraria a la estimación teórica, se sigue que es irracional, falsa, disconforme. Por tanto, cuando se da una estima práctica racional o adecuada, se sigue una afección racional, y de ésta se sigue una afección animal (orgánica) racional, y la obra exterior es, por ende, racional asimismo. Esta tesis requiere complementarse con lo que en el Compendio di etica se explicita, a saber, cuando se vuelve temática la participación de la voluntad en la formulación de la estima práctica. Resulta de gran interés que Rosmini estipule la bondad moral en términos afectivos, como se visualiza en el siguiente pasaje: "Denominamos afección a la manera en la cual la voluntad se une a sus objetos, es decir, a los entes conocidos. De donde se sigue que el bien de la voluntad y de sus actos consiste en distribuir su afección a los diversos entes conocidos en proporción y según el orden de su entidad". ${ }^{19}$

Queda así establecido que la dimensión moral no es meramente intelectiva, sino que es profundamente afectiva. Pero no se trata de afecciones ciegas y necesarias, sino justo lo contrario: afecciones inteligibles, que a su vez pueden ser racionales o irracionales. Por ello la voluntad es buena, esto es, adquiere su perfección, cuando adquiere el bien honesto, que no significa otra cosa que "el orden de la afección de la voluntad corresponda al orden del ser, objeto propio de aquella

morales o inmorales por lo mismo: porque dependen de la operación racional de estimación o valoración.

Sin embargo, el rosminianismo pide distinguir entre dos tipos de estima, a saber, la estima especulativa y la estima práctica. En la estimación especulativa, la consideración de la cosa conocida, y su comparación con otras (cuando es el caso) se detiene en la intelección, esto es, en la teorización o contemplación. Pero de ahí no se sigue una afección. Esta última se da cuando, además de la estima o juicio teórico, se da una estima o juicio práctico. Esta estima práctica sí da origen a los afectos inteligibles, los cuales son, como se dijo, racionales o irracionales, si se ajustan al objeto enjuiciado, esto es, a su verdad. Por ello es que una cosa es la ciencia o el conocimiento especulativo y otra la virtud; una cosa es el orden intelectivo y otra el orden moral, por lo cual resulta cierta la frase video meliora proboque, deteriora sequor, como recuerda Rosmini. ${ }^{18}$ Rosmini, Antonio, Storia comparativa e critica dei sistemi intorno al principio della morale, Cap. I, a. 2, p. 178.

${ }^{19}$ Rosmini, Antonio, Compendio di etica, núm. 33. "Denominiamo affezione la maniera in cui la volontà si unisce ai suoi oggetti, cioè agli enti conosciuti. Laonde il bene della volontà e de 'suoi atti consiste nel distribuiré la sua affezione ai diversi enti conosciuti in proporzione e secondo l'ordine della loro entità". 
potencia y sus actos". ${ }^{20}$ Así pues, la voluntad, que es la facultad que motiva y determina la estimación práctica, en cuanto ella es la que da inicio y finaliza la deliberación, el raciocinio práctico, es capaz de afeccionarse por cualquier ente, de suerte que lo ama más o menos, pero si quiere ser justa la voluntad, debe hacerlo, moralmente, de acuerdo con el ser de cada ente, ni más ni menos. El ser de cada ente equivale a su bondad, ${ }^{21}$ pues es amable de acuerdo con lo que es.

\section{Afectividad y las tres formas del ser}

La postura anterior conecta, de nuevo, con la Filosofia del Diritto (y puede hacerlo con la Teosofia, ciertamente). Ahí, luego de una serie de disquisiciones provechosas en torno a las afecciones y al bien, permite fijar con precisión la relación entre ser y bien, de amplia tradición filosófica: "El ser es por sí amable al espíritu intelectivo y afectivo al que se comunica; y esta relación, que llamamos ontológica, es lo que le da la denominación de bien". ${ }^{22}$ Véase la insistencia del roveretano por la dimensión afectiva; no se circunscribe su propuesta al mero intelecto, sino a la inteligencia sentiente, esto es, implica a la voluntad que se afecciona con el ente. Sin embargo, Rosmini es todavía más preciso y quien conoce su ontología trinitaria no se sorprende en descubrir que si el ser tiene tres formas primitivas, entonces hay tres estirpes de las afecciones humanas desde el punto de vista ontológico. En efecto, si el ser es real, ideal y moral, ${ }^{23}$ hay tres afecciones ontológicas primordiales que corresponden a las formas del ser. Estas tres formas del ser son primordiales en el sentido categorial, de manera que no se confunden entre sí, pero están relacionadas indudablemente. ${ }^{24}$

Ahora bien, como se revela en el texto mismo citado, Rosmini está considerando al hombre en particular al hablar de estas afecciones. No se refiere, pues, a toda entidad, sino al hombre en relación con el ser. En efecto, el ser ideal es, para él, la verdad, y origina a su vez tres

\footnotetext{
${ }^{20}$ Rosmini, Antonio, Compendio di etica, núm. 34. "Che l'ordine dell'affezione della volontà corrisponda all 'ordine dell 'essere, oggetto proprio di quella potenza e de'suoi atti”.

${ }^{21}$ Cf. Buganza, J., El ser y el bien, Edizioni Rosminiane Sodalitas, Stresa, 2010.

${ }^{22}$ Rosmini, Antonio, Filosofia del Diritto, vol. II, núm. 1023. "L'essere è per sé amabile allo spirito intellettivo ed affettivo a cui si comunica; e questo rapporto, che dicemmo ontológico, è ciò che gli dà la denominazione di bene".

${ }^{23}$ Cf. Dossi, Michele, Profilo filosofico di Antonio Rosmini, Morcelliana, Brescia, 1998, pp. 280ss.

${ }^{24}$ Cf. Buganza, Jacob, "El concepto metafísico de relación" (en prensa).
} 
afecciones, a saber: (i) la tendencia a la verdad (idealidad); (ii) la tendencia a la ciencia (realidades conocidas), y (iii) la tendencia a la virtud, que consiste en la adhesión del espíritu a las realidades conocidas de acuerdo o en proporción con la idealidad. El ser real es, por otro lado, sentimiento, es decir, presencia, de manera que origina tres afecciones más: (iv) la tendencia a amarnos a nosotros; (v) la tendencia a amar a nuestros semejantes, es decir, a toda la humanidad, y (vi) la tendencia a amar a los seres que son mayores al hombre, a saber, lo Absoluto o Infinito bajo todo aspecto. Hay en estas tendencias, que podrían ser denominadas naturales, se da una unión amorosa, una unión connatural, como se dice en el tomismo, que es más vital e íntima que el juicio meramente especulativo: "Se trata de un conocimiento cuya forma de aprehensión de la realidad se da de un modo experimental, intuitivo e impregnado de datos afectivos que preceden y acompañan a las operaciones realizadas por la razón y la voluntad". ${ }^{25}$

Finalmente, el ser moral es "sentimiento regulado por la verdad", o sea, el amor puro, universal, de donde proviene la complacencia, la benevolencia, la beneficencia, etcétera. ${ }^{26} \mathrm{Y}$ enseguida remata con estas bellas palabras que coronan su doctrina: "El ser absoluto es al mismo tiempo ideal, real y moral, de donde asume en sí la flor, la cima de toda afección de las criaturas intelectivas y volitivas. En las Escrituras es llamado caridad. Por tanto, es el vínculo más sublime, el más exquisito cemento de las voluntades humanas, que unifica, perfecciona, consuma a todos los otros". 27

Esta perspectiva ontológica, cuando vuelve a adquirir sus matices antropológicos, permiten sostener al rosminianismo tres tendencias fundamentales: intelectual, sentimental y moral. Estas tendencias fundamentales se dirigen a la verdad, al bien eudemonológico y al bien moral. Por tanto, también adquieren el nombre de "tendencia intelectual", "tendencia eudemonológica" y "tendencia moral". La proporción y orden al que se ha hecho referencia en el apartado anterior adquiere aquí nuevos bríos, pues, como si dijera inspirado en lo mejor del

${ }^{25}$ Buzueta, Sebastián, Sobre el conocimiento por connaturalidad, Eunsa, Pamplona, 2013, p. 45.

${ }^{26}$ Rosmini, Antonio, Filosofia del Diritto, vol. II, nn. 1024-1027.

${ }^{27}$ Rosmini, Antonio, Filosofia del Diritto, vol. II, núm. 1028 "L'essere assoluto è ad un tempo ideale, reale e morale, onde asume in sé il fiore, la cima di ogni affezione delle creature intellettive e volitive. Nelle Scriture è chiamato carità. Questo è dunque il vincolo più sublime, il più squisito cemento delle umane volontà, che colliga, perfeziona, consuma tutti gli altri”. 
kantismo, cuando la tendencia eudemonológica sigue a las otras dos, "siccome ancella", el hombre está ordenado, "y su obrar es armónico porque procede por una sola regla suprema. Pero cuando la tendencia al bien eudemonológico no quiere ir acompañada de las otras, y prevalecer, entonces hay desorden, el obrar es disarmónico, porque la tendencia al bien eudemonológico no puede nunca subyugar a la tendencia a la verdad (teorética y práctica)". ${ }^{28}$

Siendo el hombre un dinamismo trinitario de las tres formas del ser, debe darse la armonía entre ellas, armonía que alcanza su culmen en el orden moral, pues implica a los otros dos órdenes o formas. ${ }^{29}$ Es indudable que el hombre tiende al ser, pues el hombre es ser (aunque no el ser absoluto): ${ }^{30}$ es ser real, subsistente, y es ser ideal, en cuanto intuye la idea de ser, que le permite ser consciente de existir, de participar del ser en el tiempo, en el devenir: "Tales entes intelectivos siendo vivientes, ya que el mismo intuir al ser es sentir y vivir, esta tendencia es un sentimiento vital que se dirige hacia el ser". ${ }^{31} \mathrm{Y}$ a esta tendencia el tridentino la llama "moral", "porque viene del ser y va al ser: viene del ser intuido, que manifiesta la amabilidad esencial, y va al ser real, al cual aspira alcanzar más que nunca la forma real finita, es decir, al sujeto finito inteligente". ${ }^{32}$ Por tanto, y debido a que se trata del entrecruce entre el ser real y el ser ideal, el hombre tiende al bien en universal, al bien último por el que se afecciona, de suerte que aquí puede hablarse de un "amor natural”, como condición inicial de la voluntad. Pero puesto que el hombre es real, y no encuentra en sí todo lo que requiere para satisfacer su amor natural, tiende también a algo real que no es él, de manera que

la tendencia moral empuja y lleva al hombre [...] El tender incesante, entonces, a este otro (abandonándose a sí mismo) es tender a la fuente

${ }^{28}$ Rosmini, Antonio, Logica, núm. 228. "E il suo operare è armonico perché procede da una sola regola suprema. Ma quando la tendenza al bene eudemonologico vuol andaré scompagnata dall 'altre, e prevalere, allore c'è il disordine, l'operare è disarmonico, ché la tendenza al bene eudemonologico non può mai soggiogare la tendenza al vero (teoretico e pratico)".

${ }^{29}$ Cf. Buganza, Jacob, El dinamismo del ser trinitario en la antropología moral de Rosmini, Anthropos y Universidad Veracruzana, Barcelona, 2017.

${ }^{30}$ Cf. Nebuloni, Roberto, Ontologia e morale in Antonio Rosmini, Vita e Pensiero, Milán, 1994.

${ }^{31}$ Rosmini, Antonio, Teosofia, núm. 1037. "Tali enti intellettivi essendo viventi, giacché lo stesso intuir l'essere è sentire e vivere, questa tendenza è un vitale sentimento che si porta verso l'essere".

${ }^{32}$ Rosmini, Antonio, Teosofia, núm. 1037. "Perché viene dall'essere e va all'essere real, a cui aspira di raggiungersi più che mai la forma reale finita, cioè il subietto finito intelligente”. 
de sí mismo, a aquella fuente de la que brota, por decirlo así, su realidad propia, y donde esta realidad encuentra la esencia, la vida, la inteligencia, la perfección de todas estas cosas, el bien, la felicidad. Conviene reflexionar que la naturaleza del ente contingente es la de estar en un continuo recibir. En este acto puramente de recibir consiste todo aquello que es él. Tender al ser no es otra cosa que disponerse a recibir del ser. Y esta tendencia se efectúa por vía da la afirmación intelectiva y afectiva, de cuya afirmación nace la adhesión y, por tanto, la comunicación. ${ }^{33}$

En consecuencia, es esta tendencia moral la que regula, sobre todo, a la tendencia eudemonológica, dirigida prioritariamente a apagar la tendencia sentimental, la tendencia real, en lo cual no se agota por completo el ser del hombre. El hombre no es sólo real, sino también ideal y moral; por tanto, para alcanzar su plenitud, tiende a todo el ser, no sólo al ser real o subsistente, so pena de no encontrar la adhesión correspondiente a sus afecciones trinitarias. Por ende, el hombre, para alcanzar su plenitud, busca satisfacer sus tendencias, y el indicio más claro de éstas parece ser la afección, con sus múltiples especificaciones.

\section{Conclusión}

En este trabajo se ha partido de la definición de las Constituciones para caracterizar a la afección, que para el filósofo de Rovereto es un movimiento que se da entre el sujeto y el objeto, despertando este último en aquél un cierto interés o adherencia, esto es, una concentración que le "afecta", como se ve en la Antropologia, como una "afección universal", que impacta a todo el ser del hombre, en cuanto se difunde en él en su triple dimensión ontológica. Después se ha visto en qué consisten las afecciones de origen animal en el hombre, que se subdividen en la sexual, la sensual y la sensible. Esta última, a su vez, se divide en admiración deleitable, "gracia" y enamoramiento. Hay, a su vez, afec-

\footnotetext{
${ }^{33}$ Rosmini, Antonio, Teosofia, núm. 1037. "La tendenza morale spinge e porta l'uomo [...] Il tendere dunque incesantemente in quest'altro (abbandonato se stesso) è tendere nel fonte di se stesso, in quel fonte da cui zampilla, per così dire, la sua realità propria, e dove questa realità trova l'essenza, la vita, l'intelligenza, la perfezione di tutte queste cose, il bene, la felicità. Conviene riflettere, che la natura dell'ente contingente è quella che sta in un continuo ricevere. In quest 'atto puramente di ricevere consiste tutto ciò che egli è. Tendere nell 'essere non è altro che acconciarsi a ricevere dell'essere. E questa tendenza si fa per via d'affermazione intellettiva e affettiva, dalla quale affermazione nasce l'adesione, e quindi la comunicazione".
} 
ciones inteligibles, como nos parece correcto llamarlas y que tienen su sede propiamente en la inteligencia humana, siendo ésta esencialmente sentiente. Estas afecciones son, a su vez, racionales o irracionales, de acuerdo con la estimación práctica que el hombre realiza sobre el ser de cada entidad que conoce. De ahí el vínculo con la dimensión moral, pues las afecciones racionales se vuelven buenas desde este punto de vista, y malas (o perversas) las irracionales. Finalmente, se ha visto cómo la afectividad está incrustada ya en las tres categorías supremas del ser que propone la filosofía rosminiana. El ser ideal, que es la verdad, origina tres afecciones, a saber, la tendencia a la verdad, a la ciencia y a la virtud. El ser real, por su parte, produce afectos tendenciales en cuanto produce un amor a sí mismo, a los otros y al Absoluto. Por último, y como corona del sistema, el ser moral, en cuanto sentimiento regulado por la verdad, consiste en el amor puro y universal, que exige someter a los otros dos principios tendenciales-afectivos a sí, siendo precisamente la unión dialéctica entre el ser real y el ideal.

\section{Referencias}

Bergamaschi, C., 1982, L'essere morale nel pensiero filosofico di Antonio Rosmini, La Quercia, Génova

Buganza, J. y R. Cúnsulo, 2013, Breve esquema de antropología filosófica, Agape, Buenos Aires.

Buganza, J., 2010, El ser y el bien, Edizioni Rosminiane Sodalitas, Stresa.

—, 2017, El dinamismo del ser trinitario en la antropología moral de Rosmini, Anthropos y Universidad Veracruzana, Barcelona.

Buzueta, S., 2013, Sobre el conocimiento por connaturalidad, Eunsa, Pamplona.

De Finance, J., 1997, Etica generale, Università Gregoriana, Roma.

Deleuze, G., 1997, La filosofía crítica de Kant, trad. Marco Aurelio Galmarini, Cátedra, Madrid.

Dossi, M., 1998, Profilo filosofico di Antonio Rosmini, Morcelliana, Brescia.

Kant, I., Crítica de la razón práctica, trad. de Dulce M. Granja, Fondo de Cultura Económica, México.

Nebuloni, R., 1994, Ontologia e morale in Antonio Rosmini, Vita e Pensiero, Milán.

Rosmini, A., 1996, Costituzioni dell'Istituto della Carità, Città Nuova, Roma.

—, 2003, Nuovo saggio sull'origine delle idee, t. I, Città Nuova, Roma.

—, 1998, Psicologia, t. II, Città Nuova, Roma.

—, 1981, Antropologia in servizio della scienza morale, Città Nuova, Roma.

—, 2014, Filosofia del Diritto, vol. II, Città Nuova, Roma. 
—, 1990, Storia comparativa e critica dei sistemi intorno al principio della morale, contenida en: Principi della scienza morale, Città Nuova, Roma.

—, 1998, Compendio di etica, Città Nuova, Roma.

— , 1984, Logica, Città Nuova, Roma.

—, 2011, Teosofia, Bompiani, Milán. 